\title{
David Graeber y la antropología de la sociedad desigual
}

David Graeber and the Anthropology of Unequal Society

Una reseña del libro Debt: The First 5.000 Years*

Nueva York: Melville House, 2011, 534 páginas

KEITH HART ${ }^{* *}$

University of Pretoria, Sudáfrica

DOI: $10.22380 / 2539472 X .1839$

$\mid$

oy en día, la deuda está en todas partes. ¿Qué es la “deuda soberana” y por qué debe pagar Grecia, pero no los Estados Unidos? ¿Quién decide que la deuda nacional se pague a través de programas de austeridad y no de planes de creación de empleo? ¿Por qué los bancos son rescatados, mientras que los estudiantes y los propietarios de viviendas se ven obligados a pagar los préstamos? La propia palabra “deuda” habla de desigualdad de poder y la crisis económica mundial iniciada en 2008 ha expuesto esta desigualdad más que ninguna otra desde la década de los treinta. David Graeber escribió un libro de consulta que pretende situar nuestras preocupaciones actuales en el marco más amplio posible de la antropología y la historia del mundo. El autor parte de una pregunta: ¿por qué sentimos que debemos pagar nuestras deudas? Esta es una cuestión moral, no económica. En la lógica de mercado, el costo de los préstamos impagos debe ser asumido por los acreedores como una disciplina en sus prácticas de préstamo. Pero, mientras que pagar las deudas es bueno solo

La Revista Colombiana de Antropología agradece a Keith Hart su deferencia al permitir traducir e incluir este manuscrito en esta edición en homenaje a David Graeber. La revista realizó la corrección de estilo del texto y las adecuaciones correspondientes a las normas actuales del español. [N. de los E.]

Traducido por Margarita Chaves (mchaves@icanh.gov.co / https://orcid.org/0000-0002-90150680).

**_ johnkeithhart@gmail.com / https://orcid.org/0000-0002-8978-0191 
para unos pocos poderosos, muchos deudores se ven abocados a buscar y obtener alivio para ellas.

¿Qué es la deuda? Según Graeber, la deuda es una obligación asociada con una cifra determinada y, por lo tanto, es inseparable del dinero. Su libro dedica mucha atención a las preguntas relacionadas con el origen del dinero y lo que el dinero hace. Los estados ${ }^{1}$ y los mercados asumen por separado un papel en su creación, pero su forma ha fluctuado históricamente entre el crédito virtual y la moneda metálica. Pero, por encima de todo, la investigación de Graeber se enmarca en la desigualdad de nuestro mundo en su totalidad. El autor resiste la tentación de ofrecer remedios rápidos para el sufrimiento colectivo, ya que esto sería inconsistente con la escala de tiempo de su argumento. No obstante, ofrece a los lectores una visión del mundo en donde claramente considera que los pilares institucionales de nuestras sociedades están corrompidos y ameritan ser reemplazados. Se trata de una visión actualizada y popular. The First 5.000 Years es un best-seller internacional ${ }^{2}$. Recientemente, la traducción alemana vendió 30.000 copias en las primeras dos semanas.

En esta reseña sitúo el libro como parte de una tradición clásica a la que llamo "la antropología de la sociedad desigual” (Hart 2006), para luego referirme a lo que hace de David Graeber una figura única en la política intelectual contemporánea. Después de un resumen de los principales argumentos del libro, hago una evaluación crítica, centrada en la noción de "economía humana”.

\section{La antropología de la sociedad desigual}

La antropología moderna nació para servir a la revolución democrática que se avecinaba contra el Antiguo Régimen. Un gobierno del pueblo para el pueblo debía basarse en lo que los pueblos tienen en común, su "naturaleza humana” o sus “derechos naturales”. Escritores desde John Locke (1690) hasta Karl Marx (1867) identificaron las raíces contemporáneas de la desigualdad con el dominio social del dinero, una de las características asociadas a lo que hoy rutinariamente llamamos “capitalismo”. Para Locke, el dinero era un depósito de riqueza que permitía a algunos individuos acumular propiedades más allá de sus necesidades

1 Empleamos minúsculas iniciales en las palabras estado y gobierno, tal como aparecen en el texto original. [N. de la T.]

2 Existe traducción al español: En deuda: una historia alternativa de la economía, traducido por Joan Andreano Weyland (Barcelona: Ariel, 2012). [N. de la T.] 
inmediatas. Para Marx, el “capital” se había convertido en la fuerza motriz que subordinaba el trabajo de muchos a unas máquinas controladas por unos pocos. En ambos casos, la acumulación disolvía las viejas formas de la sociedad, pero también generaba las condiciones para su propio reemplazo por una sociedad más justa, una "mancomunidad” o “comunismo”. Sin embargo, fueron los filósofos de la Ilustración liberal del siglo XVIII quienes desarrollaron un enfoque sistemático de la antropología como fuente intelectual para rehacer el mundo moderno.

Siguiendo el ejemplo de Locke, querían fundar sociedades democráticas en lugar del sistema de clases típico de las civilizaciones agrarias. ¿Cómo se podría abolir la desigualdad social arbitraria y crear una sociedad más igualitaria basada en su naturaleza humana común? La antropología fue el medio para responder esa pregunta. Los grandes antropólogos victorianos, como Morgan, Tylor y Frazer, se apoyaron en los hombros de sus predecesores motivados por el urgente deseo de hacer que la sociedad mundial fuera menos desigual.

El libro de Kant Anthropology from a Pragmatic Point of View ([1798] 2006), un best-seller cuando se publicó, fue la culminación de ese proyecto de la Ilustración, aunque tuvo un papel marginal en la historia posterior de la disciplina. La principal fuente de la antropología del siglo XIX fue en realidad Jean-Jacques Rousseau, quien, en cuatro libros publicados en la década de 1760, revolucionó nuestra comprensión de la política, la educación, la sexualidad y el yo: El contrato social; Emilio, o de la educación; Julia, o la nueva Eloísa y Las confesiones. Para cuando se vio obligado a huir de los ataques de escuadrones alentados por la Iglesia, Rousseau ya se había labrado una reputación a través de la publicación de dos discursos, el segundo de los cuales, Discurso sobre los orígenes y fundamentos de la desigualdad entre los hombres ([1754] 1984), merece ser considerado como la fuente de una antropología que combina la crítica sobre la desigualdad de la sociedad con una política revolucionaria de emancipación democrática.

Rousseau no se preocupaba allí por las variaciones individuales de las dotaciones naturales sobre las que poco podemos hacer, sino por las desigualdades convencionales de riqueza, honor y capacidad de obediencia que pueden ser cambiadas. Para construir un modelo de igualdad humana, imaginó un estado presocial de naturaleza, una suerte de fase homínida de la evolución humana en la que los hombres, aunque solitarios, eran sanos, felices y, sobre todo, libres. Esta libertad era metafísica, anárquica y personal: los seres humanos originales tenían libre albedrío, no estaban sujetos a reglas de ningún tipo y no tenían superiores. En algún momento, la humanidad hizo la transición a lo que Rousseau llama "sociedad naciente", un periodo prolongado cuya base económica se puede 
resumir mejor como la de un cazador-recolector con chozas. Esta segunda fase representa su ideal de vida en sociedad cerca de la naturaleza.

La descomposición se estableció con la invención de la agricultura o, como dice Rousseau, con el trigo y el hierro. Aquí contradijo tanto a Hobbes como a Locke. La formación de un orden civil (el estado) fue precedida por una guerra de todos contra todos marcada por la ausencia de ley que, Rousseau insistía, era el resultado del desarrollo social y no un estado original de la naturaleza. El cultivo de la tierra dio lugar a incipientes instituciones de propiedad que, lejos de ser naturales, contenían las semillas de una desigualdad arraigada. Su culminación aguardaba el desarrollo de la sociedad política. Rousseau creía que este nuevo contrato social se había alcanzado probablemente por consenso, siendo que, en realidad, se trataba de un contrato fraudulento en el cual los ricos obtenían una sanción legal para transmitir a perpetuidad derechos de propiedad poco equitativos.

A partir de este comienzo poco propicio, la sociedad política se movió, a través de una serie de revoluciones, por tres etapas. El establecimiento de la ley y el derecho de propiedad fueron la primera etapa; la institución de los magistrados, la segunda; y la transformación del poder legítimo en poder arbitrario, la tercera. Así, el estatus de rico y pobre fue autorizado por la primera época; el de fuerte y débil, por la segunda; y el de amo y esclavo, por la tercera, que es el último grado de desigualdad y la etapa a la que finalmente conducen todas las demás, hasta que nuevas revoluciones disuelvan completamente el gobierno y lo devuelvan a la legitimidad (Rousseau [1754] 1984, 131).

El gobierno de un solo hombre cierra el círculo. "Es aquí donde todos los individuos vuelven a ser iguales porque no son nada, aquí donde los sujetos ya no tienen ninguna ley sino la voluntad del amo" (Rousseau [1754] 1984, 134). Para Rousseau, el crecimiento de la desigualdad era solo un aspecto de la alienación humana en la sociedad civil. Necesitamos retornar de la división del trabajo y la dependencia de la opinión de otros a la autosuficiencia subjetiva. Su parábola de la subversión termina con una acusación contundente de la desigualdad económica que bien podría servir de advertencia a nuestro mundo: "es manifiestamente contrario a la ley de la naturaleza, cualquiera que sea su definición [...] que un puñado de personas pueda atiborrarse de riquezas mientras que la multitud hambrienta va a la deriva” (137).

Lewis H. Morgan se basó en el modelo de Rousseau para elaborar su propia síntesis democrática de la historia humana en su obra Ancient Society ([1877] 1964). En ella utilizaba una clasificación evolutiva de estadios sociales, cada uno de los cuales se presentaba más desigual que el anterior y a los que ahora llamamos bandas, tribus y estados. La obra de Morgan se considera normalmente como el lanzamiento de la antropología moderna propiamente dicha, debido a 
su capacidad para inscribir las observaciones etnográficas contemporáneas de los iroqueses en un análisis de las estructuras históricas que subyacen a los orígenes de la civilización occidental en Grecia y Roma. Marx y Engels retomaron con entusiasmo la obra de Morgan como confirmación de su propia crítica del estado y del capitalismo. Con base en las extensas anotaciones de Marx a Ancient Society, Engels hizo su argumento más accesible en The Origin of the Family, Private Property, and the State ([1884] 1972). Su fuerte énfasis en la desigualdad de género hizo de este argumento una fuente fértil para el movimiento feminista de los años sesenta y posteriores.

Se supone que el hogar tradicional de la desigualdad es la India, y en Inequality among Men (1977) y otros libros, Andre Beteille ha hecho del tema su dominio especial, fusionando la antropología social con la sociología comparativa. En los Estados Unidos, Leslie White en Michigan y Julian Steward en Columbia dirigieron equipos - entre los que se encontraban Wolf, Sahlins, Service, Harris y Mintz - que tomaron la evolución del estado y la sociedad de clases como su principal foco de atención. Probablemente, el trabajo más impresionante que salió de esta escuela americana fue el libro de Eric Wolf Europa y la gente sin historia ([1982] 2006). Pero fue Claude Lévi-Strauss quien trató de reformular a Morgan en un solo libro: The Elementary Structures of Kinship ([1949] 1969). En Tristes tropiques ([1955] 1973), Lévi-Strauss reconoció a Rousseau como su maestro. El objetivo de Las estructuras elementales era revisar la teoría de la evolución social de Morgan en tres etapas, dibujando en un nuevo e impresionante lienzo el "eje de Siberia-Assam” y todos los puntos del Sudeste hasta el desierto australiano. Lévi-Strauss tomó como motor del desarrollo las formas de intercambio matrimonial y la lógica de la exogamia. La "reciprocidad restringida” de las bandas igualitarias dio paso a las jerarquías inestables de "reciprocidad generalizada" típicas de las tribus de las tierras altas de Birmania. Los estados estratificados de la región se volcaron hacia adentro mediante la endogamia, hacia la reproducción de las diferencias de clase y la negación de la reciprocidad social.

Jack Goody trató de rescatar nuestra profesión de una etnografía miope, a favor de un compromiso con la historia mundial que pasó de moda con el fallecimiento de los fundadores victorianos. A partir de Production and Reproduction (1976), Goody produjo en sus tres últimas décadas una serie de libros en los que se enfoca en por qué el África subsahariana difiere tan notablemente de las sociedades preindustriales de Europa y Asia, y posteriormente refuta la afirmación de Occidente sobre su excepcionalidad, en especial en comparación con Asia (Hart 2006, 2011). El hilo conductor de la compacta obra de Goody lo vincula, a través del prehistoriador marxista Gordon Childe (1954), con Morgan-Engels y, en última instancia, con Rousseau. La clave para entender las formas sociales está en 
la producción, que para nosotros significa producción mecánica. La civilización o la cultura humana está en gran medida moldeada por los medios de comunicación - anteriormente la escritura, ahora una serie de formas mecanizadas-. El lugar de las luchas sociales está en la propiedad y ahora principalmente en los conflictos sobre la propiedad intelectual. Y la cuestión central de la reproducción nunca ha sido tan destacada como en este momento, en el que los ciudadanos envejecidos de los países ricos dependen de la masa creciente de jóvenes que hay en el mundo. El parentesco también necesita ser reinventado.

\section{David Graeber: los primeros cincuenta años}

Graeber aporta la singular combinación de sus intereses y compromisos para renovar esta "antropología de la sociedad desigual". ¿Quién es él? Hijo de una pareja de intelectuales y activistas de la clase trabajadora, creció en Nueva York en los años sesenta y pasó su adolescencia en los años setenta, década bisagra de nuestros tiempos en la que una contrarrevolución "neoliberal” tomó la delantera contra la socialdemocracia de la posguerra. Esta década se enmarca en la retirada del dólar estadounidense del patrón oro en 1971 y en el aumento masivo de las tasas de interés provocado por la segunda subida del precio del petróleo en 1979. Desde entonces, la economía mundial ha estado deprimida, especialmente en su núcleo occidental. Graeber dijo que fue justo entonces, a sus dieciséis años, cuando decidió abrazar el anarquismo.

En la década de los ochenta, el préstamo irresponsable de los excedentes de petróleo por parte de los bancos occidentales a los cleptócratas del tercer mundo (Hart 2000, 142-143) y el nuevo régimen internacional de las altas tasas de interés provocaron la que se conoce como la crisis de la deuda. En la teoría de mercado, se supone que los malos préstamos deben disciplinar a los prestamistas, pero el FMI y el Banco Mundial han insistido en que cada centavo de interés añadido tiene que ser devuelto por los gobiernos de los países pobres. Este fue también el momento en el que las políticas de ajuste estructural obligaron a esos gobiernos a abrir sus economías nacionales a la libre circulación de dinero y de mercancías, con terribles consecuencias para los programas de bienestar público y los puestos de trabajo. Si la revolución anticolonial había inspirado a mi generación en el decenio de los sesenta, este saqueo al por mayor de los estados acreedores configuraría el internacionalismo de Graeber. Participó activamente en las manifestaciones contra esta nueva fase de la "globalización financiera", 
que a menudo se denomina "movimiento altermundialista” (Pleyers 2010), pero al que Graeber y sus compañeros activistas preferían llamar "movimiento por la justicia mundial”. El impacto público de este movimiento alcanzó su punto máximo en los años posteriores a la crisis financiera de 1997-1998, en particular mediante movilizaciones masivas en Seattle, Génova y otros lugares —en las que participaron el Sudeste Asiático, Rusia, Brasil y el fracasado fondo de cobertura estadounidense Long-Term Capital Management-. En su libro En deuda, Graeber afirma que, incluso, se enfrentaron al FMI y ganaron.

David Graeber obtuvo un Doctorado en Antropología en la Universidad de Chicago, gracias a una investigación etnográfica e histórica sobre una antigua aldea de esclavos en Madagascar, la cual se publicaría posteriormente como una monografía larga y ejemplar, titulada Lost People: Magic and the Legacy of Slavery in Madagascar (Graeber 2007a). La historia de la trata de esclavos, el colonialismo y la poscolonia ocupan un lugar destacado en la forma como Graeber ilustra la desigualdad global mediante un énfasis en la deuda. Antes de esto, publicó Toward an Anthropological Theory of Value: The False Coin of Our Own Dreams (Graeber 2001), una colección de ensayos sobre el valor en la que buscaba relacionar el valor económico —en especial el medido impersonalmente por el dinero-y los valores que conforman nuestra subjetividad en la sociedad. Este trabajo se basó en una revisión de las obras de Karl Marx y Marcel Mauss que proporcionó el principal recuento en inglés sobre cómo las ideas sobre el socialismo cooperativo de Mauss dieron forma a su famoso trabajo sobre el don (Mauss [1925] 1990). Un tema común en ambos libros es el papel de la magia y el fetichismo del dinero en el sostenimiento de una sociedad desigual.

La política constituye una línea central del trabajo de Graeber, con varios libros publicados hasta ahora y otros ensayos adicionales en Fragments of an Anarchist Anthropology (2004), Possibilities: Essays on Hierarchy, Rebellion, and Desire (2007b), Direct Action: An Ethnography (2009a) y Revolutions in Reverse: Essays on Politics, Violence, Art, and Imagination ${ }^{3}$ (2011c). Los títulos revelan una gama de intereses políticos que abarcan la violencia, la estética y la libido. Graeber insiste en la "afinidad electiva” entre la teoría y el método antropológico con un programa anarquista de resistencia, rebelión y revolución; y este énfasis en la "sociedad contra el estado" lo convierte en un digno sucesor de Pierre Clastres ([1974] 1989). La carrera académica de Graeber ha sido muy fructífera, sobre todo después de que Yale, a pesar de su evidente talento y productividad, lo "dejara ir”. Este hecho alimentó los rumores sobre las consecuencias académicas de sus

3 Los lectores pueden consultar la traducción al español de uno de los ensayos de este libro en el presente volumen de la Revista Colombiana de Antropología. [N. de la T.] 
actividades políticas. Estas han dado lugar a numerosos roces con la policía, pero no a un encarcelamiento prolongado, aunque su incapacidad para encontrar un trabajo en las universidades estadounidenses podría considerarse una forma de exilio.

Debt: The First 5.000 Years se publicó en el verano de 2011, año en el que Graeber se traslada a Nueva York para comenzar el año sabático de su trabajo como profesor en Londres. Allí se convierte en una presencia prominente en los medios de comunicación impresos, la televisión y los blogs, y entre agosto y septiembre contribuye a formar la primera asamblea general de la ciudad de Nueva York que dio origen al movimiento Occupy Wall Street (OWS). A él se le atribuye la autoría del eslogan de este movimiento, "Somos el 99\%”, que ayudó a imprimirle un estilo político anarquista. OWS generó una ola de imitaciones en los Estados Unidos y en todo el mundo, conocida colectivamente como el "movimiento de los okupas”, que invitaba a una comparación con la Primavera Árabe y Los Indignados de Madrid en lo que entonces parecía ser un levantamiento global. Algunos rasgos compartidos por esta serie de acontecimientos políticos, como el énfasis en la no-violencia, la toma de decisiones consensuadas y evitar la división sectaria, recuerdan la idea de Jean-Jacques Rousseau de la "voluntad general"; y no es del todo descabellado comparar la trayectoria de David Graeber hasta ese momento con la de su gran predecesor.

Graeber y Rousseau detestaban las principales instituciones del mundo en el que vivían y dedicaron sus esfuerzos intelectuales a la construcción de alternativas revolucionarias. Esto significa no conformarse con informar sobre cómo es el mundo, sino más bien explorar la dialéctica que vincula lo real con lo posible. A su vez, implica estar dispuesto a mezclar los géneros de investigación y escritura establecidos y a desarrollar otros nuevos. Ambos son escritores prolíficos con un estilo de prosa accesible, dirigido a un público masivo. Ambos alcanzaron una fama inusual para un intelectual y a ambos su práctica política los metió en problemas. Sufrieron intimidación, abandono y exilio por sus creencias. Ambos atraen la admiración y el odio en igual medida. Su originalidad es incontestable, pero cada uno puede a veces parecer tonto. No tiene sentido considerar su importancia relativa. Los paralelismos personales que señalo aquí refuerzan mi afirmación de que En deuda, de Graeber, debe verse como una continuación específica de esa "antropología de la sociedad desigual” iniciada por Rousseau hace dos siglos y medio. 


\section{En deuda: el argumento}

Gran parte del mundo contemporáneo gira en torno a los reclamos que nos hacemos unos a otros y a las cosas: propiedad, obligaciones, contratos, pago de impuestos, salarios, rentas, honorarios, etc. El libro de David Graeber Debt: The First 5.000 Years pretende iluminar estas cuestiones mediante un enfoque sobre la deuda vista desde una perspectiva histórica muy amplia. Es, por supuesto, un tema central en la política global de hoy, en todos los niveles de la sociedad. Cada día se ve otro ejemplo de una lucha de clases entre deudores y acreedores para determinar la distribución de los costos después de que el auge de los créditos se viniera abajo de manera dramática.

Podemos estar en deuda con Dios, el soberano o nuestros padres por el regalo de la vida, pero Graeber insiste, con razón, en que la lógica social de la deuda se revela con mayor claridad cuando se trata de dinero. Cita con acierto a un escritor de principios del siglo XX que insistió en que "el dinero es deuda". Este libro de más de quinientas páginas es muy rico en argumentos y conocimientos. Las notas y referencias son compendiadas y abarcan más de cinco milenios de las principales civilizaciones euroasiáticas (la antigua Mesopotamia, Egipto y el Mediterráneo, la Europa medieval, China, la India y el islam) y la etnografía de las sociedades sin estado de África, América y el Pacífico. Sus doce capítulos están enmarcados por una introducción acerca de nuestra confusión moral sobre la deuda y por un esbozo final sobre la ruptura actual en la historia del mundo que comenzó a principios de los años setenta. El argumento de Graeber se basa en la comparación antropológica e histórica más que en su comprensión de la economía política contemporánea, aunque tiene mucho que decir al respecto. También hay una corriente de cultura popular que recorre el libro y que se refuerza con un estilo de prosa destinado a cerrar una brecha entre el autor y el lector que, de otro modo, podría ser abierta por su formidable erudición.

Tal vez este aspecto del libro se pueda ilustrar con la presentación de un reciente cortometraje. Money as Debt, de Paul de Grignon (2006) —un éxito clandestino en los círculos de activistas-, se propone explicar de dónde viene el dinero. La mayor parte del dinero en circulación la emiten los bancos cada vez que hacen un préstamo. Por lo tanto, la base real del dinero, afirma la película, es nuestra firma cada vez que prometemos pagar una deuda. Los bancos crean ese dinero de un plumazo y la promesa es comprada y vendida en formas cada vez más complejas. La deuda total contraída por el gobierno, las corporaciones, las pequeñas empresas y los consumidores sube continuamente en espiral, ya que hay que pagar intereses por todo ello. Aunque la idea general es antigua, ha 
cobrado mayor relevancia en un momento en el que la oferta de dinero, que una vez pudo ser representada plausiblemente como moneda pública en circulación, ha sido superada por la creación de la deuda privada.

El intento de la película de desmitificar el dinero es admirable, pero su mensaje es engañoso. La deuda y el crédito son dos caras de la misma moneda: una evoca la pasividad frente al poder; la otra, el empoderamiento individual. En Francia y Alemania se considera que el origen del dinero es la deuda, mientras que en Estados Unidos y Gran Bretaña este origen se concibe tradicionalmente como crédito. Cualquiera de los dos términos, deuda y crédito, está cargado y, al separarlos, se pierde el carácter dialéctico de las relaciones involucradas. El dinero como deuda demoniza a los bancos y a los intereses en particular, dejando al público fuera de juego al no mostrar el papel activo que la mayoría de nosotros desempeña en el sostenimiento del sistema. En la actualidad, el dinero lo emite una red mundial dispersa de instituciones económicas de distintos tipos, y la norma del crecimiento económico se alimenta de un deseo generalizado de autosuperación y no solo del interés bancario.

David Graeber ofrece mucho más que esto, por supuesto; su libro también se alimenta de corrientes populares, lo que no es sorprendente, dado el tiempo que pasa fuera del aula y de su estudio. Su marco analítico se explica con gran detalle en seis capítulos. Los dos primeros abordan los orígenes del dinero en el trueque y la "deuda primordial" respectivamente. Muestra con fuerza y elegancia lo inverosímil que es el mito liberal estándar del origen del dinero como medio de intercambio, pero también rechaza el mito nacionalista de la teoría principal que se le opone y que traza el origen del dinero como medio de pago y unidad de cuenta del poder del estado. En el primer caso, sigue a Polanyi ([1944] 2001), pero en el segundo, pone de relieve la interdependencia de los estados y los mercados en el origen del dinero. Un breve capítulo muestra que el dinero siempre fue tanto una mercancía como una deuda (Hart 1986), lo que dio lugar a muchas disputas políticas y morales, especialmente en el mundo antiguo. Siguiendo a Nietzsche, Graeber argumenta que el dinero introdujo por primera vez una medida de las relaciones desiguales entre el comprador y el vendedor, el acreedor y el deudor. Mientras que Rousseau rastreó la desigualdad hasta la invención de la propiedad, Graeber ubica las raíces de la servidumbre humana, la esclavitud, el tributo y la violencia organizada en las relaciones de endeudamiento. Las contradicciones del endeudamiento, alimentadas por el dinero y los mercados, condujeron a las primeras religiones del mundo a articular nociones de libertad y redención para responder al creciente conflicto de clases entre acreedores y deudores, que a menudo implicaba llamamientos a la cancelación de la deuda. 
El autor expone luego su historia positiva para contrarrestar aquella propuesta por la corriente principal de la economía liberal. Su ensayo sobre los fundamentos morales de las relaciones económicas hace explícita su crítica al intento de construir "la economía” como una esfera separada de la sociedad en general. Esto se debe en parte a la tríada universal de mecanismos distributivos de Polanyi (1957) — reciprocidad, redistribución y mercado- que aquí se identifican como "comunismo cotidiano", jerarquía y reciprocidad. Por el primer término Graeber entiende la capacidad humana de compartir o la "sociabilidad de base"; el segundo se confunde a veces con el tercero, ya que las relaciones desiguales se representan a menudo como relaciones de intercambio - usted me da sus cosechas en contraprestación para no ser golpeado- La diferencia entre jerarquía y reciprocidad es que la deuda es permanente en el primer caso y pasajera en el segundo. Las clases medias en Occidente entrenan a sus hijos para que digan "por favor” y "gracias” como una forma de limitar la deuda contraída al recibir algo. Los tres principios están presentes en todas partes, pero su énfasis relativo está matizado por las formas económicas dominantes. Por ende, el "comunismo" es indispensable para las prácticas de trabajo modernas, mientras que el capitalismo es una pésima manera de aprovechar nuestra capacidad humana para la cooperación.

Los dos capítulos siguientes introducen lo que para mí es la idea principal del libro: el contraste entre las “economías humanas” y las dominadas por el dinero y los mercados - Graeber prefiere llamarlas “economías comerciales” y a veces, "capitalismo"-. Primero identifica las características independientes de las economías humanas y luego muestra lo que sucede cuando se incorporan por la fuerza a la órbita económica de las “civilizaciones” más grandes, incluida la nuestra. Esta es, hasta cierto punto, una gran teoría de la división de la historia, aunque, como insistiría Mauss, en las sociedades capitalistas persisten elementos de la economía humana. Hay un cierto sentido en el que las "economías humanas” corresponden a un mundo que hemos perdido, pero que podría recuperarse después de la revolución. Graeber (2011a) se esmera por señalar que esas sociedades no son necesariamente más humanas, solo "son sistemas económicos que se preocupan principalmente no por acumular riqueza, sino por crear, destruir y reorganizar a los seres humanos” (130). Utilizan el dinero, pero básicamente como "monedas sociales" cuyo objetivo no es adquirir cosas, sino mantener las relaciones entre las personas.

"En una economía humana, cada persona es única y de valor incomparable, porque cada una constituye un nexo único de relaciones con los demás” (Graeber 2011a, 158). No obstante, gracias a las formas monetarias de que disponen, es 
posible tratar a las personas como cuantitativamente idénticas, lo cual supone un cierto grado de violencia. La brutalidad - no solo conceptual, sino también física- está presente en todos los casos, aunque más en unos que en otros. Esta violencia es inseparable del dinero y la deuda, incluso en las economías más "humanas" en las que es habitual apartar a las personas de su contexto familiar. Esto, sin embargo, se lleva a otro nivel cuando se involucran sistemas como el comercio de esclavos del Atlántico o de los imperios coloniales occidentales de antaño. La siguiente reflexión extendida sobre la esclavitud y la libertad - una pareja que Graeber considera impulsada por una cultura de honor y endeudamiento- culmina en la contradicción última que sustenta la economía liberal moderna, una visión del mundo que concibe a los individuos como socialmente aislados, de una manera que solo podría haber sido preparada por una larga historia de esclavitud de los pueblos conquistados. Puesto que no podemos aceptar fácilmente este relato de nuestra propia historia, no es sorprendente que confundamos la moralidad y el poder cuando pensamos en la deuda.

Hasta aquí, Graeber se ha basado en gran medida en material antropológico, especialmente de las sociedades africanas, para ilustrar el mundo que transformó Occidente, aunque su relato de los orígenes del dinero se basa en gran medida en el ejemplo de la antigua Mesopotamia. Ahora formaliza su teoría del dinero para organizar un compendio de la historia del mundo en cuatro etapas: la era próxima al 300 a.C. aproximadamente, que vio las primeras civilizaciones urbanas; la Edad Axial que, de manera bastante inusual, data del 800 a.C. al 600 d.C. 4; la Edad Media (600-1450 d.C.); y la edad de "los grandes imperios capitalistas”, desde 1450 d.C. hasta la ruptura simbólica del dólar americano con el patrón oro en 1971. Como esta última fecha sugiere, la periodización se basa en gran medida en las oscilaciones históricas entre los grandes tipos de dinero. Graeber llama a estos "créditos” y "lingotes”, es decir, dinero como una medida virtual de las relaciones personales, como pagarés y como moneda o cosas impersonales hechas de metales preciosos para la circulación.

El dinero comenzó siendo una unidad de cuenta, administrada por instituciones como templos, bancos y estados, en gran parte en cuanto una forma de medir las relaciones de deuda entre las personas. La moneda se introdujo en el primer milenio como parte de un complejo que vinculaba la guerra, los soldados mercenarios, la esclavitud, el saqueo, las minas, el comercio y el aprovisionamiento de los ejércitos en movimiento. Graeber llama a esto el "complejo

$4 \quad$ Hart anota lo inusual de esta periodización, puesto que la cronología propuesta por Graeber dista de la canónica establecida por Karl Jaspers para esta era, que culmina en el 200 a. C. [N. de la T.] 
milicia-moneda-esclavitud" del que Alejandro Magno, por ejemplo, fue un maestro. De ahí que nuestra palabra soldado se refiera a su paga. Los llamados "años oscuros” de la Edad Media ofrecieron cierto alivio ante este régimen, ya que durante la mayor parte del periodo medieval las monedas metálicas escasearon y el dinero volvió a tomar la forma dominante de crédito virtual. India, China y el mundo islámico se enlistan aquí para complementar lo que sabemos de Europa. Sin embargo, el descubrimiento del Nuevo Mundo abrió la fase que conocemos del último medio milenio, cuando el imperialismo occidental revivió la tradición más antigua de guerra y esclavitud lubricada por lingotes de oro.

Las últimas cuatro décadas son obviamente de transición, pero el reciente incremento del dinero del crédito virtual sugiere la posibilidad de otro gran giro en la historia, alejado de los principios que sustentaron el mundo que hizo Occidente. Podría tratarse de un mundo multipolar, más parecido a la Edad Media que a los dos últimos siglos. Podría ofrecer más posibilidades para las "economías humanas” o, al menos, para las “monedas sociales”. La crisis de la deuda podría provocar revoluciones y luego, quién sabe, la cancelación de la deuda en los términos del antiguo jubileo. Tal vez todo el complejo institucional basado en los estados, el dinero y los mercados o el capitalismo será sustituido por formas de sociedad que respondan más directamente a la gente del común y a su capacidad de "comunismo cotidiano".

Todo esto se aborda en el capítulo final. Pero Graeber deliberadamente deja estas "conclusiones políticas” poco claras. Su objetivo en este libro ha sido llevar a sus lectores a una visión de la historia de la humanidad que va en contra de lo que hace que sus predicamentos sociales sean supuestamente inevitables. Es una visión inspirada en parte por su profesión como antropólogo, en parte por su compromiso político como activista. Ambos compromisos evitan la elaboración de programas para que otros sigan. Ocuppy Wall Street ha sido criticado por no enumerar una lista de “demandas”. Sin duda, podría decirse lo mismo de este libro, pero así los lectores, incluido este crítico, se inspirarán en él de manera concreta para imaginar posibilidades que su autor no podría haber previsto.

\section{Hacia una economía humana}

David Graeber y yo inventamos el término “economía humana” de forma independiente durante la última década (Graeber 2009b, 2011a; Hart 2008, Hart, Laville y Cattani 2010). Los editores de The Human Economy: A Citizen's Guide 
se distanciaron, en la introducción y en nuestro enfoque editorial, de cualquier escatología "revolucionaria” que sugiriera que la sociedad había llegado al final de algo y que pronto se lanzaría a una trayectoria completamente nueva. La idea de una "economía humana” llamaba la atención sobre el hecho de que las personas hacen mucho más por sí mismas de lo que sugeriría un enfoque exclusivo en las instituciones económicas dominantes. En contra de una noción singular de la economía como “capitalismo”, argumentamos que todas las sociedades combinan una pluralidad de formas económicas y varias de ellas se distribuían a lo largo de la historia, aunque su combinación estuviera fuertemente coloreada por la forma económica dominante en determinados tiempos y lugares.

Por ejemplo, en su famoso The Gift: The Form and Reason for Exchange in Archaic Societies ([1925] 1990), Marcel Mauss demostró que otros principios económicos estaban presentes en las sociedades capitalistas, y que entender esto proporcionaba una base más sólida para construir alternativas no capitalistas que el intento de la Revolución bolchevique de romper totalmente con los mercados y el dinero. Karl Polanyi también, en sus diversos escritos, insistió en que la economía humana a lo largo de la historia combinaba varios mecanismos de los cuales el mercado era tan solo uno. Argumentamos, por lo tanto, que la idea de una transformación radical que llevara de una economía concebida monolíticamente como el capitalismo a su opuesto era una forma inapropiada de enfocar el cambio económico. Deberíamos, más bien, prestar atención a todo el espectro de lo que la gente ya está haciendo y construir iniciativas económicas alrededor de este, con el fin de darles una nueva dirección y énfasis, en lugar de suponer que el cambio económico tiene que ser reinventado desde cero. Aunque esto parece un enfoque gradualista de la mejora económica, su adopción generalizada tendría consecuencias revolucionarias.

La política anarquista de David Graeber informa su análisis económico; siempre ha adoptado una posición antiestatista y anticapitalista, con los mercados y el dinero generalmente subsumidos bajo el concepto de capitalismo. Es decir, él ve el futuro basado en lo opuesto a nuestros estados capitalistas. El núcleo de su política es la "acción directa” que ha practicado y sobre la que ha escrito como etnógrafo (Graeber 2009a). En The Human Economy sostenemos que la gente en todas partes depende de una amplia gama de organizaciones en su vida económica: mercados, estados nación, corporaciones, ciudades, asociaciones de voluntarios, familias, redes virtuales, economías informales, delincuencia. Deberíamos buscar una mezcla más progresiva de estas cosas. No podemos permitirnos dar la espalda a las instituciones que han ayudado a la humanidad a hacer la transición a las sociedades del mundo moderno. Las burocracias a gran escala coexisten con muy variadas formas de autoorganización popular y 
tenemos que hacer que trabajen juntas en lugar de que lo hagan con propósitos cruzados, como ahora ocurre a menudo.

Graeber también cree, como hemos visto, que la vida económica en todas partes se basa en una combinación plural de principios morales que adquieren una complexión diferente cuando son organizados por las formas dominantes. Por lo tanto, ayudarse mutuamente como iguales es esencial para las sociedades capitalistas, pero el capitalismo distorsiona y margina esta predisposición humana. Con todo, Graeber parece esperar una ruptura radical con los estados capitalistas relativamente pronto y esto se refleja en su teoría de las etapas de la historia, con categorías que se corresponden. A primera vista, estas posiciones -llamémoslas "reforma” y "revolución" - son incompatibles, pero los recientes acontecimientos políticos - los movimientos Primavera Árabe y Ocuppy Wall Street de 2011, por más indeterminados que sean sus resultados inmediatosapuntan a la necesidad de trascender esa oposición.

La brecha entre nuestros enfoques para humanizar la economía está, por tanto, reduciéndose. Aun así, hay diferencias de teoría y método que apuntan a algunas reservas residuales que tengo sobre el libro de la deuda. La primera de ellas se refiere a la preferencia de Graeber por agrupar los estados, el dinero, los mercados, la deuda y el capitalismo, junto con la violencia, la guerra y la esclavitud como sus habituales compañeros de cama. El dinero y los mercados tienen cualidades redentoras que, en mi opinión (Hart 2000), podrían aplicarse a fines económicos progresivos en formas no capitalistas; tampoco creo que las instituciones modernas como los estados, las corporaciones y la burocracia se extingan pronto. El anticapitalismo como estrategia revolucionaria plantea la cuestión de la pluralidad de las instituciones económicas modernas. Como mostró Mauss (Hart 2007), las economías humanas existen en las grietas de las sociedades capitalistas. David Graeber parece estar de acuerdo, al menos cuando se trata de encontrar allí el "comunismo cotidiano” y, al negarse a sanear las "economías humanas” en su forma prístina, él modifica la división categórica e histórica que las separa de las economías comerciales. Aunque los binarios revolucionarios parecen aflorar en varios puntos de su libro, su visión antropológica está marcada también por una tendencia subyacente a discernir la continuidad de las prácticas económicas humanas.

Un argumento del alcance de En deuda no había sido hecho por ningún antropólogo profesional durante la mayor parte de este siglo y menos aún por alguno de tanta relevancia contemporánea. La disciplina abandonó en gran medida la "historia conjetural" en el siglo XX para abrazar las perspectivas locales más estrechas que ofrece el trabajo de campo etnográfico. Las obras de comparación amplia, como las de Wolf y Goody, fueron la excepción a esta tendencia. 
Inevitablemente, los métodos de Graeber serán objeto de escrutinio, no solo por parte de colegas profesionales, sino también por el público en general. (Él me decía que los académicos ya no leen las notas a pie de página, pero los legos sí.) Para este lector, la primera mitad del libro - que se basa en gran medida en fuentes etnográficas para explicar el argumento- es más sistemática, tanto en términos de coherencia analítica como de documentación, que la segunda —que se ocupa de dar cuerpo a los ciclos de historia que propone el autor-. En cualquier caso, Graeber apenas intenta analizar la economía política contemporánea. Aunque hace una referencia más explícita a ello que la de, por ejemplo, Mauss en Ensayo sobre el don -en el que da por sentada la comprensión de los lectores de los mercados capitalistas-, en ninguna parte de su libro Graeber menciona la revolución digital en las comunicaciones de nuestro tiempo ni su alcance para transformar las economías, ya sean humanas o comerciales (Hart 2000, 2005).

Bueno, pero eso no es del todo cierto, ya que el autor introduce ocasionalmente anécdotas basadas en el conocimiento común o personal. El problema es que muchos lectores que confían en lo que tiene que decir sobre la antigua Mesopotamia o el Tiv pueden encontrar estas historias contradictorias por su propio conocimiento. Es algo parecido al "síndrome de la revista Time": aceptamos lo que Time tiene que decir sobre el mundo en general hasta que impacta en lo que conocemos y entonces su credibilidad se disuelve. El ejemplo de Apple Computers es famoso: fue fundada por ingenieros informáticos —en su mayoría republicanos-que se separaron de IBM en Silicon Valley en la década de los ochenta y formaron pequeños círculos democráticos de veinte a cuarenta personas con sus computadoras portátiles en los garajes de cada una (Graeber 2011a, 96). Tanto la veracidad de esta anécdota como la erudición del autor han sido cuestionadas por numerosos blogueros californianos. Graeber es consciente de las dificultades de hacer alusiones contemporáneas. En el capítulo final (2011a, 362-363) introduce inteligentemente un mito urbano sobre el oro almacenado bajo el World Trade Center y luego (casi) lo rehabilita utilizando fuentes documentadas. Afortunadamente, David Graeber no se ha visto disuadido por los pedantes y ha mantenido su intención de cruzar la línea entre el conocimiento académico y el conocimiento general en este libro; como resultado, sus lectores se benefician inmensamente.

Contribuí a la propaganda del editor para este libro y dije que es "el mejor antropólogo erudito que conozco". Me sostengo en eso. El larguísimo ensayo que ha publicado recientemente sobre la divina realeza del Shilluk (Graeber 2011c) abarca el mismo terreno que han abarcado varios antropólogos famosos desde Frazer en adelante, pero con un rango de erudición insuperable y una perspectiva política democrática. De todas formas, cuando se escribe un libro como este, 
es inevitable que la policía logre atraparlo en alguna ocasión. Es una obra de inmensa erudición y merece ser celebrada como tal.

Nuestro mundo sigue siendo enormemente desigual y puede que estemos entrando en un periodo de guerra y revolución comparable a los "segundos Treinta Años” de guerra, 1914-1945, que sobrevino la última vez en que, durante varias décadas, el imperialismo financiero quebró. El propio capitalismo hoy parece haber vuelto a la búsqueda de rentas como una norma que lo asemeja más a la desigualdad arbitraria del Antiguo Régimen que a la de la industria victoriana. La aspiración a la democracia económica es ahora más esquiva que nunca; sin embargo, la humanidad ha ideado también medios de comunicación universales adecuados, por fin, para la expresión de ideas universales. Jean-Jacques Rousseau habría aprovechado esta oportunidad y varios sucesores ilustres lo hicieron a su manera durante los dos últimos siglos. Necesitamos una antropología que esté a la altura del desafío que hoy nos plantea nuestro común dilema humano. Nadie ha hecho más para enfrentar ese desafío que David Graeber, en su trabajo como un todo, pero especialmente en este libro.

\section{Referencias}

Beteille, Andre. 1977. Inequality among Men. Blackwell: Oxford.

Childe, V. Gordon. 1954. What Happened in History. Harmondsworth: Penguin.

Clastres, Pierre. (1974) 1989. Society against the State: Essays in Political Anthropology. Nueva York: Zone Books.

De Grignon, Paul, dir. 2006. Money as Debt. Canadá, Moonfire.

Engels, Friedrich. (1884) 1972. The Origin of the Family, Private Property, and the State. Nueva York: Pathfinder.

Goody, Jack. 1976. Production and Reproduction: A Comparative Study of the Domestic Domain. Cambridge: Cambridge University Press.

Graeber, David. 2001. Toward an Anthropological Theory of Value: The False Coin of Our Own Dreams. Nueva York: Palgrave Macmillan.

-. 2004. Fragments of an Anarchist Anthropology. Chicago: Prickly Paradigm.

-. 2007a. Lost People: Magic and the Legacy of Slavery in Madagascar. Bloomington, IN: Indiana University Press.

-. 2007b. Possibilities: Essays on Hierarchy, Rebellion, and Desire. Oakland, CA: AK Press. 
-. 2009a. "Debt, Violence, and Impersonal Markets: Polanyian Meditations". En Market and Society: The Great Transformation Today, editado por Chris Hann y Keith Harth, 106-132. Cambridge: Cambridge University Press.

-. 2009b. Direct Action: An Ethnography. Baltimore, MD: AK Press.

-. 2011a. Debt: The first 5,000 Years. Nueva York: Melville House.

-. 2011b. "The Divine Kingship of the Shilluk: On Violence, Utopia, and the Human Condition or Elements for an Archaeology of Sovereignty”. Hau. Journal of Ethnographic Theory 1 (1): 1-62. https://doi.org/10.14318/hau1.1.002

-. 2011c. Revolutions in Reverse: Essays on Politics, Violence, Art, and Imagination. Nueva York: Autonomedia.

Hart, Keith. 1986. "Heads or Tails? Two Sides of the Coin”. Man 21 (4): 637-656. https://doi. org/10.2307/2802901

-. 2000. The Memory Bank: Money in an Unequal World. Londres: Profile.

-. 2005. The Hit Man's Dilemma: Or Business Personal and Impersonal. Chicago: Prickly Paradigm.

-. 2006. "Agrarian Civilization and World Society". En Technology, Literacy and the Evolution of Society: Implications of the Work of Jack Goody, editado por D. Olson y M. Cole, 29-48. Mahwah, NJ: Lawrence Erlbaum.

-. 2007. "Marcel Mauss: In Pursuit of the Whole 'A Review Essay". Comparative Studies in Society and History 49 (2): 473-485. https://doi.org/10.1017/S0010417507000564

-. 2008. "The Human Economy”. ASA online UK, 6 de diciembre. https://www.theasa.org/ publications/asaonline/articles/asaonline_0101.shtml

-. 2011. Jack Goody's Vision of World History and African Development Today. Goody Lecture 2011. Halle: Druckerei; Max Planck Institute for Social Anthropology.

Hart, Keith, Jean-Louis Laville y Antonio David Cattani, eds. 2010. The Human Economy: A Citizen's Guide. Cambridge: Polity.

Kant, Immanuel. (1798) 2006. Anthropology from a Pragmatic Point of View. Cambridge: Cambridge University Press.

Lévi-Strauss, Claude. (1949) 1969. The Elementary Structures of Kinship. Boston: Beacon.

—. (1955) 1973. Tristes tropiques. Londres: Cape.

Locke, John. (1690) 1960. Two Treatises of Government. Cambridge: Cambridge University Press.

Marx, Karl. (1867) 1970. Capital. Vol. 1. Londres: Lawrence \& Wishart.

Mauss, Marcel. (1925) 1990. The Gift: The Form and Reason for Exchange in Archaic Societies. Londres: Routledge.

Morgan, Lewis H. (1877) 1964. Ancient Society. Cambridge, MA: Bellknapp. 
Pleyers, Geoffrey. 2010. Alter-globalization: Becoming Actors in a Global Age. Cambridge: Polity.

Polanyi, Karl. (1944) 2001. The Great Transformation: The Political and Economic Origins of Our Times. Boston: Beacon.

-. 1957. "The Economy as Instituted Process". En Trade and Market in the Early Empires, editado por Karl Polanyi, Conrad M. Arensberg y Harry W. Pearson, 243-269. Glencoe, IL: Free Press.

Rousseau, Jean-Jacques. (1754) 1984. A Discourse on Inequality. Harmondsworth: Penguin.

Wolf, Eric. (1982) 2006. Europa y la gente sin historia. Ciudad de México: Fondo de Cultura Económica. 